\title{
Change Towards Excellence
}

\author{
Jozef Ritzen
}

\section{Introduction}

This chapter deals with the challenges of change towards excellence for universities that find themselves embroiled in the turmoil of globalization and of "informatization": the intense absorption of ICT (information and communication technology) in even the tiniest blood vessels of social and economic life. External change leads to new and different demands on university output requiring welltrained graduates and research and community engagement (Sect. 2).

The university leadership plays a crucial role in ensuring that change towards excellence is achieved by developing a strategy which is owned by the university and by providing the means for that strategy's implementation (Sect. 3). In Sects. 4, 5, and 6 the elements of the strategy, involving goals in education, research, and community engagement, are discussed, as are the means to achieve these goals. Regional alliances appear to be a necessary component of a strategy leading towards excellence for most universities (Sect. 7). Section 8 discusses some questions concerning implementation, while Sect. 9 is devoted to concluding remarks.

This chapter draws on my personal, almost nine-year long, experience as minister, responsible for education, science, and culture in the Netherlands during the 1990s. The Netherlands' universities currently belong among the top 100 of most university rankings in relation to population size. The legislative changes effected in the 1990s are, according to many observers, related to the quality increase in universities that followed some 10-20 years later. Also, as President of Maastricht University in the first decade of the twenty first century, I learned a great deal about change towards excellence. The University grew to become perhaps the only university world-wide completely based on problem-based learning in all degree courses. In 2014 it was ranked 6th in the Times Higher Education Ranking of the

\footnotetext{
J. Ritzen $(\bowtie)$

Maastricht University, Maastricht, The Netherlands

e-mail: j.ritzen@maastrichtuniversity.nl 
"50 under 50" (the top 50 universities in the world younger than 50 years old), with in excess of $50 \%$ of foreign students in its student body. Strategy towards excellence, based on past performance and strength, aided in the achievement of that position. The high ranking was never the primary goal, but it turned out to be an inevitable by-product of the university's search for excellence.

\section{The Times Are Changing, and so Are Universities}

\subsection{Internal Change}

It is felt by some people that universities are the only places in the world where time stands still. They believe that someone who left the classroom 50 years ago may return and discover everything still the same. Two years ago a then recently appointed president of one of the European top universities that had been established centuries ago remarked in a private meeting that he was glad that nothing had changed in his institution during its long history. I met him again recently and his perspective had changed significantly. Certainly, the beautiful buildings were still there and many of the centuries old customs and rites were still in use. Yet under that surface of continuing age-old traditions everything had changed, or was in the process of changing.

The orientation in education has been changing its focus towards the latest skill requirements (in the broadest sense) as perceived in society and the labor market. The approach to education has been changing with the advent of student-centered and ICT-learning's integration in blended learning. The approach to research is changing, taking research increasingly in the direction of protected knowledge in patents and the use of knowledge for start-ups or spin-offs, without ignoring fundamental research. Community engagement has also been discovering new direction, as is well described by Professor Wilhelmsson in chapter Excellence in Serving Society and Mankind.

The organization of universities has also been changing in a convergence between a full recognition of the professionals and strong leadership in practically horizontal relations. Universities have increasingly become partners in regional, national, and sometimes international networks with private business and local and national governments, as is well explained by Professor Su in chapter Excellence in Education. Universities have started to cooperate among themselves both on the level of education and of research. University networks have been established as venues for the sharing of managerial, educational, and research experiences. This occurs at the national level and internationally, sometimes involving mergers and sometimes with joint Master's or doctoral programs.

Also, the context in which universities are operating is undergoing changes. Unfortunately, it can be seen that in many countries, society's faith in the responsibility of universities for the common good has weakened, creating a tendency for government regulatory overload and limiting universities' empowerment [1]. Universities serve an important role for society, which is the reason for substantial 
levels of government funding for university education and research. This important role for society can best be played in the form of partnerships between universities and governments, with full university empowerment and accountability; as opposed to the situation in which universities are overloaded with well-intentioned government regulations, leaving them less than adequate room for maneuver to adapt to rapidly changing external environments.

\subsection{External (to the University) Change}

The past 50 years have seen tremendous changes in our societies. No one foresaw as late as the year 1990 that the mobile phone would conquer the world. No one could have foreseen the current actuality where online web information and messages reach to and are accessible in even the most remote villages. The impact of this has forced shops to close down in some areas due to the high volume of Internet purchases in virtual shops. Neither could it have been foreseen that three terabytes of information ${ }^{1}$ could be stored on a single disk costing less than $\$ 200$ and that it could be analyzed in a few seconds, whereas in 1990 it would have taken days or weeks with a warehouse of interconnected disks. Routine work is being mechanized or robotized on a scale we never could have imagined.

Not only have we witnessed a tremendous change on the technological side, but we also have witnessed the breakdown of trust in the financial system in scandals like Enron and later the US/European Banking Crisis, where it came to be realized that even the best education did not necessarily guarantee high ethical and moral standards. We also see an increase in armed conflict in societies with highly educated populations. Apparently, we have not learned at home or in school how to resolve conflicts through peaceful means.

These changes have impacted not only the way we live, but also the way we create wealth in a hopefully sustainable manner. Innovation in products or production has become essential in order to realize the high margins associated with being first on the market. Innovation is the source of labor productivity which helps to raise wages. This can only happen sustainably with sufficient trust in the functioning of our markets and our societies.

In this context, universities have become central in generating sustainable economic growth through their graduates and through their research and are an important source of innovation. The high growth regions in Europe and the US are all located in areas that are locations of venues for the provision of quality higher education. The Boston area in the US and the Cambridge area in the UK are excellent examples. The migration of highly skilled manpower and entrepreneurship is toward such high growth regions, thus creating an upward spiral.

\footnotetext{
${ }^{1}$ A terabyte is $1000 \mathrm{~GB}$ or $1000 \times 1000 \mathrm{MB}$. The first hard disks I used in the $1980 \mathrm{~s}$ had a capacity of $5 \mathrm{MB}$.
} 


\subsection{Converting and Adapting External Change into Change Within the University}

Most universities, older and younger, were taken unawares by the tidal wave of external changes in recent years. The changes were observed by leadership, staff, students, and stakeholders, but were hardly reflected in the content or in the organization of universities. Universities themselves were fully engaged in the "going concern", making sure that "the show went on" and allowed themselves little time to reflect on the implications of the external changes for the content or the organization of their education, research, and community engagement. In the 1990s this started to change, often engendered by governments.

I was a close witness of this process in the 1990s as the minister responsible for higher education and science in the Netherlands, while being in close contact with other ministers in the European Union. In some cases the leadership of universities were willing to engage in change, yet were restrained from doing so by legislation, which proved difficult to change as it was defended by coalitions of students and staff and was sometimes reinforced by stakeholders.

Change is always fraught and problematic: you know what you have and you don't know what you will get. Conservatism and being inimical to change are very human characteristics. Change can only be brought about by dialog between all involved parties and with trust in leadership based on past performance and on the experienced empathy of leadership with staff and students. Change always has a cost in terms of readjustment and relearning. Change is also fun. It keeps you alive and presents new opportunities and horizons.

A broad dialog concerning change is necessary for change to catch on. Stakeholders are involved in this process of consultation and dialog. However, stakeholders may feel that they have a strong interest in maintaining the status quo. An example of this was in the Netherlands in the 1990s when organized employers and organized employees (trade unions) were not at that time willing to be partners with universities in change, but were rather advocates of maintaining the status quo. Technical university education (which I had myself benefited from) was organized around a curriculum of 5 years which on average would actually take 7 years, as had been the case since the early inception of technical university education in the later part of the nineteenth century. This clearly was too long a study time-frame for every student in the period of mass technical university education. Yet around the year 1995 it was employers who were the most antagonistic to the introduction of a bachelor/Master's system with a 4-year maximum duration. Several factors may explain this. First there may have been the expectation of more costs for firms for in-service training once the length of time for study courses was reduced. Second there seemed to be the psychological reason that business leaders wanted the up and coming generation to receive the same education as they had themselves received.

Change is visible in a university strategy which has "teeth" and contains choices. These choices identify what the university wants to stand for and the 
manner in which it wants to proceed to this stature. Choices are clear and cannot be everything for everyone. Choices also involve compromise and by their very nature generally barely reflect the ideal as some would like to see it.

Most universities are organizations of a substantial size. The larger the size of an organization, the less nimble it is likely to be. There are many examples of large organizations which have thought of avoiding the conservatism induced by size, through a mix of central strategy on main lines, while also leaving a lot of available room for decentralized adaptation and responsibility. I am convinced that universities, definitely the larger ones, should also opt for such an approach in order to make the strategy work.

\section{Strategies for Excellence}

\subsection{Elements}

Obviously, education and research are central in any university strategy, while community engagement might be counted as a third goal of universities. But there is also the need for inspiration, for a choice on the culture universities want to exude. Few universities or university departments have been able to encapsulate this in a single sentence or motto. Most often, vague lines are chosen like "entrepreneurial" or "innovative" university. I came across a good example of a university which found a condensed way of describing its culture at the Free University in Amsterdam. In 2013 that university selected three core values: personal (in the sense of the staff setting the examples), open (to students from all different backgrounds), and responsible (meaning: engendering a spirit of responsibility towards society among staff and students). Another good example is Harvard Business School (HBS) which stated in 2014, “... we believe that leadership and values are inseparable. The teaching of ethics is explicit, not implicit, and our community values of mutual respect, honesty and integrity, and personal accountability support the HBS ..." [2]. A university wants to make a specific choice in the cultural values it pursues. This is not a mere choice of the right words, but should be visible in the implementation of the strategy. It should be explicit and one should be accountable for it, as HBS wants to be.

The choice for HBS was not unintended. Graduates of HBS were involved in many of the financial scandals in the US. HBS wanted to demonstrate that it had learned from experience, setting in this way an example for other business schools.

\subsection{No Copycat. Differentiation Is the Name of the Game}

One of the main headaches for governments in the past decades has been, and still is, the tendency for universities to all target the comfortable middle zone of the 
student market. Universities have shown themselves to be reluctant to change in this respect, in the same manner as the ice cream sellers who all like to stand the main entrance to the beach, avoiding positioning themselves at the other entrances where perhaps fewer people are entering. The comfortable middle is one with a lot of competition (many ice cream sellers), but also with the comfort that it is a stable time-tested position, in particular when student numbers are increasing.

At the same time, there are different students with different talents and different ambitions. Also, the labor market has many dimensions. There is no "one size fits all" in the demand for graduates. Yet, the forces opposed to differentiation are considerable. Research universities often feel obliged to expand their scope by broadening the range of degree courses they offer to include non-research based elements, more appropriate for university community colleges for applied sciences, in order to attract additional students. Conversely community colleges or their equivalents feel that they are undervalued and strive for more research, for master degrees, or even for Ph.D. programs for inclusion in their proffered educational packages. Both cases involve reductions in quality for students in one way or another because the ensuing quality dilution is across the board. There is global recognition that there are at least four differentiated levels of higher education: the community colleges, the universities of applied sciences, the bachelor colleges, and the research universities. Roughly, some 60-80\% of the students are in the industrialized countries in the community colleges and universities of applied sciences and 20-40\% in colleges and research universities (OECD, Education at a Glance, 2014). It appears that in countries which follow this division the research universities are better placed in international rankings than in countries where less differentiation takes place.

Universities themselves should feel responsible for their position. Often, however, governments have to interfere to induce differentiation as universities are not able to resist the temptation of growth and universities of applied science are unable to avoid the insecurity of feeling undervalued. Increasing numbers of governments now also want to enter into performance agreements with universities so that universities choose specific profiles distinguishing them from others. Lack of clarity and visibility in universities' profiles is often due to governments' unwillingness to provide finance to universities for undifferentiated profiles.

The choice for differentiation is not only along the broad lines, but can also relate to specific student demands. Some universities seem to do very well for students from a non-traditional background (e.g., children of immigrants) and could make this a point of differentiation. Others are pioneers in new approaches to education like Olin College in Boston or Maastricht University, both utilizing a problem-based approach to learning in all of their courses. The Open Universities are examples of a differentiated approach, as are the newly emerging Internet universities such as the Khan Academy. A university can only opt for such a profile if it fits into a "business case", i.e., that the university can sustain itself financially. 


\subsection{The University Owns the Strategy}

The strategy implementation stands or falls with the process of strategy preparation. The strategy should be prepared in such a way that it is "owned" by the broader leadership of the university. These are the Board, the deans, key professors as well as some carefully selected student leaders and promising young staff. External stakeholders might also be included. The voice of alumni can also be important. Broad consultations are often viewed as a waste of time: academics are busy with education, research, or community involvement, and are not focused on or engaged in "strategy". Also external stakeholders have to be convinced that they can actively contribute to the university strategy and that doing so is in their own interest. The costs in terms of time of the leadership, of faculty, and of stakeholders, as well as the costs of organizing consultations should not be underestimated. At the same time the result, in terms of ownership, is well worth the outlay.

\subsection{Supporting the Development of a Strategy}

Naturally ("we are as a university involved in the pursuit of the truth"), the discussions on future strategy are based on extensive research on our own position and strengths and include the nature and composition of the external environment. A SWOT analysis is an important starting point, not only concerning finance, satisfaction of students and alumni, external assessment of the quality of the curricula and research quality, but also in terms of the quality and culture of the organization. Recently the University of Cologne requested an outside Agency to conduct such a SWOT analysis for its Central Organization [3]. Cultural aspects were included in the analysis.

An important part of research is the exploration of the potential scope and space for maneuver (maneuverability potential). To what extent is the present situation determined by government regulations and what is the scope and space available for change? It often happens that perceptions of maneuverability potential are based on and limited by historic personal experience. The organizational autonomy, i.e., the ability of the university to set its own goals and priorities through an adequate governance structure, may be underrated. The financial autonomy (the ability to decide on its own finances) could be undervalued. More substantial investments using borrowed funds might be possible if innovative methods of selling research products can be developed. Also, on the policy side, there might be more maneuverability available than was initially presumed to be the case.

Funding remains an important issue. What is the potential for increasing funds, through grants, through partnerships with the private sector, through partnerships with local governments or the national government, through philanthropy, and perhaps through alumni? 
International and national advisory boards may be able to widen actionable scope. As chapter International Advisory Boards in the World shows with examples: top universities, or universities which strive towards excellence, will, as a rule, try to acquire and utilize international knowledge and experience for developing and implementing strategies which imply substantial change.

\section{Strategic Positions on Education}

\subsection{Goals and Means}

Strategic positions on education center on goals (what is the purpose of our education) and means (how such goals are achieved).

\subsection{Goals}

"Demand driven" university education with elements of entrepreneurship is likely to be considered as a self-evident starting point for a debate concerning goals. Many universities view "demand driven" as being "student centered". That would do injustice to the fact that universities should have clear ideas about what students should acquire, what students should learn, and what skills students should develop. The more ambitious universities will take as their starting point in this regard the knowledge of what skills, competencies, and knowledge are required for graduates to function effectively and successfully in the labor market and in wider society:

- Cognitive achievement and knowledge of the field remain of predominant importance.

- The majority of work is done in communication and cooperation with others. Being able to work in teams and communicate effectively are essential job requirements.

- Employers like graduates to be problem solvers.

- Most graduates of internationally recognized universities work in an international environment.

- Most graduates of internationally recognized universities understand ICT.

Harvard Business School added that such graduates should have developed a strong sense of integrity.

Other universities hold that graduates' crucial attributes should include the development of social responsibility or civic engagement.

Strategic choices may be simple to state in words concerning these issues, though their integration into individual degree courses may yet prove difficult. There we see resistance to change because the integration has to render the skills 
and competency demands explicit. Let me give an example of the implementation of the strategic notion that students should be prepared to work in an international environment. In 2008, Maastricht University thought that this notion could be integrated into degree courses by formally requiring all students to spend at least one semester abroad at a foreign university. Several directors of degree courses complained. They reasoned that implementation of this requirement would be problematic and could not easily be fit into the regular curriculum and that it would result in graduates completing their courses insufficiently prepared in terms of knowledge for entry into the workplace and society. This illustrates potential pitfalls in the terrain to be covered in strategy implementation.

Universities who are free to decide the number of students to be admitted may also want to think about strategic positions in terms of the number of students to be admitted (if the government allows restrictions). They may also want to take into account the selection procedures for courses where the more academically able students may have access to "enriched" classes and they may also want to consider the throughput rate (avoiding dropout after selection or after a first trial year).

Universities may want to display excellence in the manner they assist graduates in securing gainful employment through placement services or otherwise. This process should be integrated into the degree programs themselves and should not be merely something that follows graduates' degree completion as a kind of afterthought.

Entrepreneurship education is another element of education in which the university can make choices: should such courses be offered, should participation in such courses by voluntary (not for credit or for credit), should it be compulsory, and if so, what other subjects should be dropped in degree courses to make curricular space for entrepreneurship inclusion?

\subsection{Means}

The means for delivering excellent education are people. It is important to realize time and time again that universities are a people business. It is the university staff members who make, or unfortunately possibly break, the quality of the university. Human resource policy is an important element that involves having the right people in the right places, investing in motivation and continued learning, and investing in facilities which make it possible for staff to achieve the proper life-work balance, such as by the provision of adequate child care facilities. A number of other strategic issues must also be considered here, such as tenure track careers for scientific staff, promotion possibilities, the ratio of junior to senior staff and of scientific staff to "support staff", developmental opportunities available for staff, and financial remuneration (increases) and promotion policies among other things. In many OECD universities, gender policy is an important topic: while the majority of the students are female, the majority of the senior professors are male, with 
insufficient attention having been paid to status quo change in this regard in recent decades. The supply pipeline of senior female professors is problematic: with every step taken in scientific staff seniority, the percentage of female staff falls significantly (often above $50 \%$ among post docs, decreasing to often around $20 \%$ among senior professors).

Means are also pedagogical. It is remarkable how readily the well-established learning pyramid is ignored.

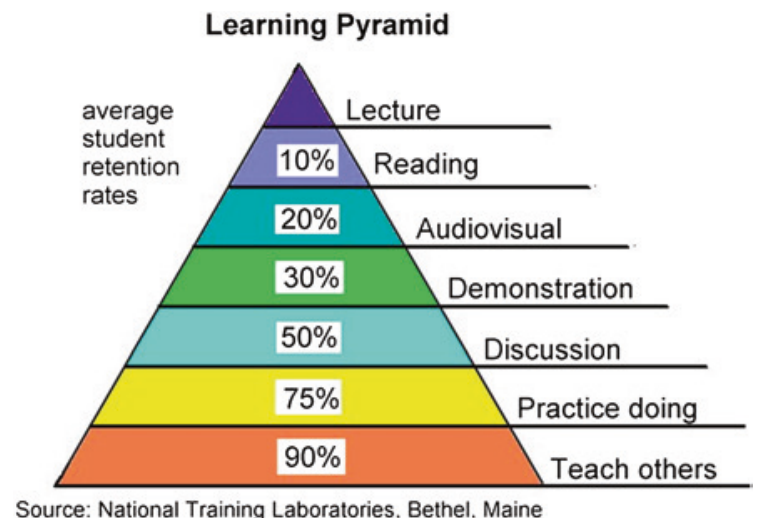

How can it be that most universities still rely mainly on large lecture hall teaching, if the efficiency in terms of retention rates is so low? Is it because universities were physically constructed with this educational method in mind? If that is so, then there is a clear case for renovation in tandem with learning process innovation through small group teaching and learning. Increasingly, universities are moving in the direction of problem- or research-based learning where small groups, practice, teaching others, and learning problem solving are blended [4].

\section{Strategic Positions on Research}

\subsection{Research for Publications}

Some universities have the idea that their research strategy should focus in particular on raising the number of publications which are cited world-wide, in order to achieve the likelihood of raising their ranking levels. Even if this is the case, substantial strategic elaboration on the manner in which this is to be accomplished is still required. It is likely to imply focus as not every department or every research group within the departments is going to be a winner in this regard. Established research groups with good track records could form part of the focus, but so might new emerging groups with potential. Strategic choices are also dependent on the 
selection of the areas universities want to excel in, in terms of their academic and social profiles and overall perspectives.

Such strategic deliberations are fraught with strife and it is generally a complex process to ascertain and enumerate how universities' research budgets are to be distributed as a result of research strategies.

Citations and potential citations should not be the sole considered criteria. Also, the contribution of universities to their immediate or wider educational, social, and commercial environments could be an important point of departure with research strategy aiming to increase the volume of public-private co-publications.

Generally research strategies would also aim to utilize universities' potential to acquire grants from a variety of other external sources.

An overriding factor for consideration concerning research is the level of its contribution to the satisfaction of societal curiosity and the level of its contribution to a problem's solution. Often universities are so deeply involved in research that they do not have time to think. A research strategy should also allow for fundamental research which may not lead instantly to publications in top journals because of its "off the beaten track" nature.

\subsection{Research Supporting the Quality of Education}

Most universities realize how important their research is to enable academic staff to guide the students' learning process, as is well explained by Professor Arthur in chapter Excellence in Research. Learning has more quality the more it is based on the creative exploration of facts and their interrelations and interconnections in what might be the most relevant theories. Research is important for staff to encourage students to refrain from rote learning and to instill in them what might be called "the Einstein attitude". He stated this attitude after having formalized the relativity theory which replaced the Newtonian way of thinking. He said, "We now have a way of interpreting more of what we see. But make no mistake: there might be even more appropriate theories". The relativity theory was thinking "out of the box", not in deepening the Newtonian theory. Learning is at its best when it leads to such an attitude, such a way of thinking.

This may be different from publishing in the majority of peer-reviewed journals with relatively low impact factors, as peers will often judge contributions by their progress along the well-travelled beaten track. This deepening of knowledge may be useful, yet for research-based education the "out of the box" thinking is of more significant importance. Top journals, such as The Lancet and Nature and their equivalents in the social sciences and humanities with high impact factors, are focusing on novel ideas and concepts. University staff accepted to publish in such journals would presumably be best equipped to guide and facilitate students' learning using methods intended to replace students' reliance on the conventional rote-learning comfort zone. 
Most universities face a dilemma as top researchers' publications are important for universities' reputations, while their contribution to education is either nonexistent, or imprecisely observed and recognized in rankings and in more qualitative peer perceptions. Researchers themselves also often face such dilemmas as they may want to actively contribute to education while they are at the same time aware that their research publications are more important for their own careers, in particular if they are still on tenure track.

Change towards excellence implies also discovering the correct balance between the involvement of the best researchers in their research undertakings and in education. The introduction of research-based learning elements in the curriculum may provide a helpful means of bridging this gap.

\section{Strategy on Community Engagement}

In parliamentary or other public discussions on higher education, the goals of universities are often laid out in three interconnected strands: education, research, and community engagement. Community engagement is closely related to what is called the social responsibility or "service" of universities as their "third mission." This role of universities is central to the educational experience of students and to the commitment of universities to wider society. There are many dimensions of the role of service [5]. The most important service universities render to society is the quantity and quality of their graduates. Also the contribution of research to regional and national economic development is highly relevant. This includes collaboration with regional and national governments and industry to improve technology, assistance to industry to improve practice, support for the integration of new technologies, and the direction of new knowledge towards societal advancement (see the following section).

Universities use different models for the "soft side" of the third mission for civic and community involvement of students and their social entrepreneurship. These contribute to the social responsibility of graduates while at the same time improving the quality of life for different sectors of society. The importance of engaging higher education students through broad-based participation in civic society for the development of the skills and attitudes of socially responsible graduates is achieved through curriculum and related projects. For this to succeed, it is crucial that university staff members are committed to the notion of socially responsible and highly productive graduates. 


\section{Strategies on Partnerships}

\subsection{Region to University Interaction}

Universities, even those with high international profiles, have a significant impact on the local regions in which they are located while the regions in turn provide fertile environments for the universities. There appears to be something of an upward causal spiral in these interrelationships. Regions considered excellent in terms of growth in regional products and labor productivity and that are highly attractive destinations for new businesses and for bright young people are generally regions with high quality universities. That is not to say that universities only operate for the benefit of their own localities or regions, and the facts show that current graduates are likely to display levels of mobility that preclude many of them from remaining in the regions in which they graduated. A substantial part of the research on this topic is in the public domain and readily accessible in relevant publications. In spite of this, high educational and academic quality universities turn out to be part of strong regions. Research facilities of private industries seek locations in close proximity to those of good universities. Princeton in USA and Louvain in Belgium provide clear examples in this regard. The regions benefit as high quality universities are attractive as sources of competent labor and as sources of inspiration in open networks, while the universities benefit as it is easier for them to attract staff and research grants in booming regions than it is for universities in other economically less-advantaged locations.

Change towards excellence for universities then is a process in which the regions and the universities have to both partake in regional strategic planning. It concerns locating, identifying, and strengthening the threads of the upward spiral, creating and working in partnerships. Formal regional partnerships, between local governments, local industries, and universities, are intrinsic to any strategy for change. Strategic options of universities are reinforced by, or may be altered according to and in alignment with, regional agreements.

Region-university interaction existed in the Netherlands in the stage of the elite universities. One of my Alma Maters, the Technical University of Delft, had been founded in part as support for the development of major Netherlands-based industries such as Shell, Philips, AKZO, and Unilever and had a tremendous impact on the region. Yet, by 1980 the university's formal and practical ties with the region and the regional government had ceased and they operated and existed as separate entities with minimal contact. From the 1960s to the 1990s new universities were established throughout Europe with low levels of formal linkage to the regions in which they were located.

It was only in the past 10-20 years that the awareness grew that change towards excellence for universities could be reinforced by strong cooperation with the regions in which universities are located, and that regions for their part came to realize the tremendous capital that universities represented for their development. 
Developing strong regional cooperation is a time-consuming and lengthy process. It is also a process with its ups and downs. Regional governments change with the political cycle and the new guard may have different notions than their predecessors. However, there are numerous examples of successful cooperation between universities and the regions, such as in the cases of Louvain or Princeton (previously mentioned), and Warwick (UK) and Copenhagen (Denmark).

\subsection{International Partnerships with Other Universities}

Most universities have extensive links with other universities in education and research. In education there are substantial levels of student exchange, sometimes as features of joint degree programs. In research, individual researchers or research groups often collaborate in joint programs or on an informal basis. These partnerships can be part of a strategic line of focus. They can be left to individual departments or degree courses or they can be decentralized under a central general framework, as is, for example, the case in Cambridge. In this case, the International Strategy Office helps coordinate and facilitate agreements between individual departments/schools/colleges and international partners under a protocol governing all such international agreements.

There were times when a university president might have informed visitors of the 300 or more signed memoranda of understanding with other universities, while being at a loss and unable to demonstrate how they actually contributed to the university's quality of research and teaching. This has changed as nowadays universities have highly selective cooperation agreements with other universities which stipulate how exactly joint degrees or joint research projects are conducted and identify their structural frameworks in terms of finance and accountability.

\section{Implementation}

\subsection{Measurement}

Successful implementation requires measurement. How well are we doing on the strategic lines we set out? Education performance, for example, can be measured approximately by:

- Graduate (un)employment rates (university role in linking with labor market);

- High levels of graduates' satisfaction with their studies 3 years subsequent to graduation;

- High levels of employers' satisfaction with graduates 3 years subsequent to graduation;

- Student questionnaires on satisfaction with education (numerous examples in Germany and the Netherlands);

- Student-course-evaluations. 
Measures of research performance are widely and readily available, such as in citations, public-private scientific publications, etc. All of these measures are to be strategically refined. Does the university want graduates to have a high level of international understanding? If the answer is in the positive, then this level of international understanding requires appropriate measurement. Qualitative scales are available. It is a challenge to show not only how graduates score, but also how scores have changed during degree courses and how this has been achieved. HBS wants to contribute to the integrity of graduates. This is required to be measurable (again, qualitative scales are available, for example the Giotto scale [6]).

\subsection{Incentives}

Incentives in education are generally the most difficult to come by, as the career of the professor seems so overwhelmingly determined by the research performance of the staff member. Education prizes and professorial education careers have turned out to be helpful instruments in incentivizing educational quality.

Incentives could also be made available in monetary terms, linking the quality of degree program to budget allocation levels. The inherent danger here that has to be acknowledged is that what are perceived as being underperforming programs face the threat of becoming financially squeezed. For such programs special treatment may be a solution, as the quality problems are often persistent and not cured by purely financial remedies, but require major staffing and structural changes. Budget allocation can also be based in part on graduate numbers or on the throughput rate in degree courses.

Personal incentives can also be applied in monetary terms for individuals, such that only those that perform well receive annual increases, while those whose performance is rated as excellent receive additional financial rewards. Dismissals for serious underperformance should also be invariably available to universities striving for excellence.

\subsection{Balanced Score Cards}

Many universities render their strategy implementation visible through the use of balanced score cards. These score cards are also a means of making universities' performance accountable to external environments. Such score cards might enumerate the aims for the number of graduates, for successful accreditation of programs, for student and graduate satisfaction, for research performance, for the attraction of international students and staff, and for female professors among other things. 


\section{Concluding Remarks}

Change towards excellence is based on a converging process of involvement of staff, students, and stakeholders in setting the goals for education, research, and community engagement in line with the rapidly changing external environment. Choices are derived from this process: where do universities want to stand in a differentiated setting in the country with some universities being more and others less research intensive, while facing various and changing demands from students and the labor market?

Most universities are seriously challenged both in relating their education to labor market demands in terms of skills and competencies and in the manner in which they organize the students' learning (with excessive predominance of large lecture hall teaching). They need to explore and implement innovative learning in small groups using blended learning tools. Teachers are required to organize learning and become visible academic and educational role models. Research- and problem-based education should be incorporated into, and become an intrinsic element in, universities' educational processes.

Both in education and in research, regional compacts are emerging as means and pathways to effectively organize the context for change to excellence.

Open Access This chapter is distributed under the terms of the Creative Commons Attribution Noncommercial License, which permits any noncommercial use, distribution, and reproduction in any medium, provided the original author(s) and source are credited.

\section{References}

1. University policy needs to beef up for Europe to be more innovative. (2014). www.empowereu.org

2. www.hbs.edu/mba/student-life/Pages/leadership-and-values.aspx

3. UzK Evaluation ZV Peer Bericht. (2014). (In German; translated: University of Cologne Peer Evaluation).

4. Soete, L. (2014). Contribution to the IECHE Conference Riyadh, April 2014.

5. Riyadh Conference Statement on the Social Responsibility of Universities, IECHE. (2013). ieche.com.sa/portal/en/2013

6. http://www.getfeedback.net/products/detail/giotto 